\title{
PAISAGENS DE SÃO PAULO \\ NO TEMPO E NO ESPAÇO
}

JACQUELINE MYANAKI

\section{RESUMO:}

AS PAISAgENS POLIMORFAS dA CIDADE dE SÃO PAULO, A MAIOR METRÓPOLE dA AMÉRICA LATINA, CUJAS TRANSFORMAÇÕES, COM CARACTERÍSTICAS MARCADAMENTE CONTRASTANTES, SÃO EXAMINADAS A PARTIR dAS REPRODUCÕ̃ES DE DEZ QUADROS DE PAISAGENS PINTADOS POR ARTISTAS BRASILEIROS, ENTRE 1893 E 2001, CONSTITUEM O OBJETO dE ANÁlISE DESTE trabalHO. A ANÁLISE E LEITURA DESTES QUADROS PINTADOS POR ANTÔNIO PARREIRAS, TARSILA DO AMARAL, FRANCISCO REBOLO, MÁrIO ZANINI, AGOSTINHO BATISTA DE FREITAS E GREGÓRIO GRUBER, PERMITE USUFRUIR DO ASPECTO COGNOSCITIVO DA ARTE EM FAVOR DA ANÁLISE DA PAISAGEM EM GEOGRAFIA. ESTA ABORDAGEM BUSCA SOMAR AOS MÉTODOS DE ANÁLISE E INVESTIGAÇÃO GEOGRÁFICA, A ANÁLISE E REFLEXÃO DE OBRAS DE ARTE, CONSIDERANDO A PAISAGEM PINTADA COMO UM REGISTRO DE ELEMENTOS OBJETIVOS E SUBJETIVOS QUE PODEM REVELAR MUITO dA CULTURA dE UM POVO E SEU TEMPO, SUAS diNÂMICAS DE FORMAC̦̃̃O E TRANSFORMAC̦Ão, BEM COMO CONDICIONAR NOVOS OLHARES E PERCEPC̄̃̃ES SOBRE A PAISAGEM.

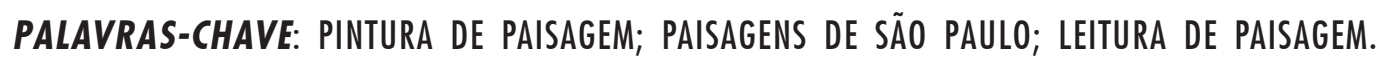

São Paulo, a maior metrópole da América Latina, é uma referência em termos de velocidade de transformações na paisagem nos últimos cem anos. Com características marcadamente contrastantes, números gigantescos dentre suas estatísticas e o caos e a ordem delineando suas paisagens polimorfas, São Paulo é o cenário sobre o qual este trabalbo se debruça.

Este trabalbo propõe a análise de pinturas de paisagens como parte de uma abordagem para a compreensão dos símbolos e signos da paisagem geográfica, entendendo que a arte é também uma forma de apreensão do mundo, permitindo-nos desvendar a dinâmica de formação e transformação dessa paisagem e também construir um novo olhar e percepção sobre a mesma (Myanaki, 2003, p.34). 
INTRODUÇÃO

Para examinar as transformações da paisagem da cidade de São Paulo desde fins do século XIX até o início deste século XXI, propõe-se utilizar a leitura de dez reproduções de quadros pintados por artistas brasileiros em diferentes momentos. Dentre os pintores estão Antônio Parreiras, Tarsila do Amaral, Francisco Rebolo, Mário Zanini, Agostinho Batista de Freitas e Gregório Gruber.

Alguns desses pintores foram participantes do chamado Grupo Santa Helena, cujo trabalho era voltado para o registro do cotidiano e arredores da cidade de São Paulo. Outros como, Agostinho Batista de Freitas possuem experiência não acadêmica na arte de pintar, é o chamado artista naif, porém todos têm em comum o fato de em algum momento de suas carreiras terem retratado paisagens da cidade de São Paulo.

Com técnicas e materiais diversos cada um dos dez quadros selecionados representam paisagens da cidade de São Paulo, num momento diferente, desde 1893 até 2001, período abrangido pelas paisagens pintadas.

A escolha dos quadros foi realizada a partir de uma seleção, de aproximadamente 260 reproduções digitais de paisagens de pintores brasileiros, realizada durante a pesquisa do mestrado. Dentre essas reproduções foram selecionadas dez paisagens pintadas da cidade de São Paulo e que correspondem a épocas diferentes dentro de um período de pouco mais de um século. Buscou-se a maior variedade possível de pintores e a menor variedade possível de locais retratados dentro do perímetro da cidade.

Uma maior variedade de pintores foi escolhida para garantir uma maior diversidade de olhares e percepções sobre a cidade, no intuito de multiplicar os pontos de vista como afirma Claval (in: Corrêa \& Rosendahl, 2004) ao discorrer sobre o papel do geógrafo que analisa a paisagem, justificando para este trabalho a utilização do diálogo entre arte e geografia e tornando compatíveis discursos e promovendo uma relação estética entre o indivíduo e a paisagem (Myanaki, 2003, p.34).

A escolha da menor variedade de lugares foi no intuito de permitir um acompanhamento nas mudanças da paisagem ao longo do tempo. Dentro das reproduções disponíveis foram encontradas uma maior quantidade de paisagens da área central da cidade, ora se afastando um pouco, ora se aproximando mais. Dessa forma foi possível restringir a análise à área central, uma vez que a cidade de São Paulo é portadora de múltiplas paisagens.

Considerando-se que o centro da cidade de São Paulo é simbolicamente o "coração da cidade" e que, nesse caso, "a parcela do espaço estudado faz parte de uma totalidade, que pelo seu estudo da parte podemos compreender melhor o processo de construção/reconstrução do espaço" (Alves, 2004, p. 290), então a escolha da área central permanece bem indicada.

Partindo da noção que uma paisagem pintada, um quadro é um registro de elementos objetivos e subjetivos que podem revelar muito da cultura de um povo e seu tempo (Myanaki, 2003, p.33), utilizá-lo na análise da paisagem em geografia, permite ao geógrafo desvendá-la como marca e matriz, como descreve Berque (in: Corrêa \& Rosendahl, 1998):

\footnotetext{
A paisagem é uma marca, pois expressa uma civilização, mas é também uma matriz porque participa dos esquemas de percepção, de concepção e
} 
de ação - ou seja, da cultura - que canalizam, em um certo sentido, a relação de uma sociedade com o espaço e com a natureza e, portanto, a paisagem de seu ecúmeno. E assim, sucessivamente, por infinitos laços de co-determinação.

Transpondo a idéia de marca e matriz para o método, a arte, neste trabalho, não é considerada como um ponto de partida fixo, mas sim como uma etapa da análise da paisagem geográfica, podendo-se recorrer a ela em diferentes momentos da análise e retornando a ela a qualquer momento sempre que se fizer interessante um novo olhar sobre o olhar fixado na tela.

\section{Paisagem na Arte e na Geografia}

O conceito de paisagem não tem o mesmo significado na arte e na geografia, porém aproximar arte e geografia é uma forma de promover esclarecimentos sobre a polissemia do conceito e ainda ampliar a experiência sobre as paisagens para melhor conhecê-las, como afirma Tuan (1974, p. 110):

\section{A apreciação da paisagem é mais pessoal e du-} radoura quando está mesclada com lembranças de incidentes bumanos. Também perdura além do efêmero, quando se combinam prazer estético com a curiosidade científica.

O conceito de paisagem existe anteriormente à organização da ciência geográfica no século XIX, mas não existiu sempre e nem é comum a todas as sociedades. Muito mais identificado com as artes plásticas do que com a geografia inicialmente, o termo surge na Europa por volta do século XVI.
$\mathrm{Na}$ arte ocidental, paisagem é um gênero da pintura cujo apogeu ocorreu no século XIX e que posteriormente sofreu oscilações no grau de importância e nos padrões de representação (Myanaki, 2003). É a "representação pictórica de um sítio ao ar livre, no qual a natureza desempenha o papel exclusivo ou preponderante."

No século XIX, artistas como Thomas Ender, Johann Moritz Rugendas e Adrien Aimé Taunay acompanharam expedições multidisciplinares no Novo Mundo a fim de registrar a flora, a fauna, a diversidade humana, enfim, as paisagens dessas terras ainda não exploradas.

Os desenhos e pinturas realizados por esses artistas compunham, em parte, o material científico produzido pelos pesquisadores, naturalistas e viajantes. É assim que a pintura de paisagem esteve junto da investigação científica. Não raro, os geógrafos dessa época, também desenhavam e pintavam. Já no século XX, Pierre Deffontaines (1894-1978) realizou mais de 3.000 desenhos (Hérodote: Revue de Géographie et de Géopolitique, 1987, p. 66) de paisagens. (Myanaki, 2003, p. 15).

O interesse pelo conceito de paisagem, na geografia, posto de lado no século XX em detrimento de conceitos como região, espaço, território e lugar, é retomado, principalmente a partir da década de 1970, com abordagens inovadoras como a identificação da paisagem como texto ou como imagem cultural.

$\mathrm{Na}$ arte ocidental, após o impressionismo, no final do século XIX a pintura de paisagem modifica-se, rompendo com os referenciais renascentis- 
tas e a geometria perspectivista. Os experimentos de luz e cor e as pinceladas rápidas com o intuito de registrar rapidamente a luminosidade daquele instante, resultam em paisagens e percepções inovadoras - é o impressionismo.

Novos fenômenos são inseridos nas paisagens pintadas, como os raios. Também novos padrões de representação e simbolismo modificam as paisagens, trazidos principalmente pelos surrealistas e posteriormente pelos abstracionistas, a ponto de F. Dagognet (in: Riou, 1986) afirmar que a paisagem morreu.

$\mathrm{Na}$ verdade o que se nota é que as transformações nas paisagens pintadas ocorrem simultaneamente ao processo de transformações das paisagens geográficas.

Entre 1850 et 1950, les paysages urbains occupent une place importante dans les différents arts. La rue, le boulevard, le mouvement des bommes et des choses, les réclames et les vitrines, les terrasses de café, le luxe et la pauvreté s'y déclinent sous leurs nombreuses facettes diurnes et nocturnes. (Béguin, 1995, p.17)²

A partir do início do século XX, o gênero paisagem já não corresponde mais àquela definição em que a natureza tem papel preponderante. As paisagens pintadas revelam outras naturezas das paisagens, outras percepções, talvez não se trate mais simplesmente de pinturas de paisagens, mas sim de paisagens em pinturas (Grout, 1992).

Se considerarmos que a arte revela "um sentido das coisas e faz com que um particular fale de modo novo e inesperado, ensina uma nova maneira de olhar e ver a realidade, e estes olhares são revelado- res sobretudo porque são construtivos, como o olho do pintor, cujo ver já é um pintar e para quem contemplar se prolonga no fazer" (Pareyson, 1984, p. 25) então é possível usufruir do aspecto cognoscitivo da arte em favor da análise da paisagem em geografia.

\section{INTERESSE GEOGRÁFICO NO GÊNERO PAISAGEM}

A compreensão de uma obra de arte passa por diversos itens, para este trabalho interessa tudo que contribuir para esclarecer e elucidar aspectos da história cultural e o passado da cidade de São Paulo, em especial sua área central.

Poucas paisagens culturais são inteiramente produtos de trabalbo de comunidades contemporâneas. A evolução de uma paisagem é um processo gradual e cumulativo - tem uma bistória. Os estágios nessa bistória têm significados para a paisagem atual, assim como para as do passado. Além disso, as paisagens culturais do mundo refletem não apenas evoluções locais, mas também grande número de influências devido a migrações, difusão, comércio e trocas." (Wagner e Mikesell, in: Corrêa \& Rosendabl, 2003, p. 39)

Assim, foi dedicado um espaço para uma pequena biografia dos pintores, pois como afirma Pareyson, trata-se de "iluminar as obras através da biografia, já por sua vez iluminada pelas próprias obras" (Pareyson, 1984, p. 96), ou seja, uma biografia orientada pela arte e sem um fim em si mesma, apenas interessando o que pode contribuir para o esclarecimento das paisagens de São Paulo.

Cada um dos quadros foi minimamente analisado em seu assunto, tema, conteúdo e forma, des- 
vendando aspectos sobre as paisagens de São $\mathrm{Pau}-$ lo em dado momento histórico, uma vez que a análise dos processos numa paisagem cultural envolve a abordagem de sua história cultural.

Antônio Diogo da Silva Parreiras (Niterói-RJ, 1860 - Niterói-RJ, 1937) apesar de ter se dedicado a diversos gêneros da pintura, notabilizou-se sobretudo como paisagista. Suas paisagens românticas e históricas refletem parte de seus estudos junto aos irmãos Grimm e a experiência de pintar ao ar livre.

O quadro "Chácara da Consolação" (fig. 01) de 1893 de Antônio Parrreiras, retrata uma paisagem da São Paulo de fins do século XIX, com sutis toques românticos. O artista valoriza a luminosidade refletida na propriedade e nos jardins como pode-se notar pelas sombras em perspectiva no canto inferior direito e também na lateral esquerda. Apesar de comprimida pelos muros, a natureza é um dos elementos mais valorizados da paisagem, vindo logo a seguir da superfície lisa do solo da avenida em primeiro plano, os jardins da chácara ocupam toda a parte central da paisagem. Seguindo a linha de perspectiva da base do muro, à direita, surge a casa sede, retratada como elemento de menor importância.

A maneira equilibrada e simétrica de compor esta paisagem é típica dos arranjos paisagísticos do período. "Chácara da Consolação" pode ser dividido em três partes no sentido horizontal. Uma faixa inferior referente ao solo, uma faixa central retratando uma porção da grande propriedade e a faixa superior do céu cuja monotonia é quebrada unicamente pelo avanço do pinheiro ao centro.

Os tons pálidos do quadro seguem uma tendência do temperamento do artista que preferia as horas tristes do dia por entendê-las como horas de repouso. Como acontecia, no período, com boa parte das chácaras em São Paulo, a Chácara da Consolação era utilizada somente para curtas temporadas por seus proprietários, portanto há um paralelo entre este fato e o repouso aparente da composição, cuja valorização das linhas retas confere pouca movimentação e pouca dramaticidade ao quadro. O que se confirma pela ausência de figuras humanas na composição.

A artista paulista Tarsila do Amaral (CapivariSP, 1886 - São Paulo-SP, 1973) tem importância indiscutível para a história da arte brasileira pelo conjunto de sua obra, mas sobretudo pela produção da década de 1920 quando se destacam suas obras das fases "Pau-Brasil" e "Antropofágica", com características primitivistas nas cores e nas formas.

É justamente com o uso das chamadas cores "caipiras", em tons fortes, que Tarsila retrata uma das paisagens de São Paulo da década de 20. O quadro "São Paulo" (fig. 02) de 1924 é uma representação paisagística que rompe com o conceito acadêmico de paisagem. A luz que incide na representação é direta sem a convenção das sombras que a luz natural provoca nas diversas horas do dia e muito valorizada nas paisagens "clássicas". A profundidade revela-se pela diminuição de elementos sem adoção dos recursos da perspectiva. A forma tem influência das vanguardas cubista e construtivista, mas apresenta-se de maneira absolutamente original, inaugurando uma iconografia que marcaria boa parte da obra da pintora, com linhas duras e fechadas, contornos nítidos.

Porém a temática, ao contrário do que acontece com as obras cubistas, tem relevância para Tarsila, e no caso do quadro "São Paulo", a artista re- 
vela uma cidade já com fortes contornos tipicamente urbanos e modernos no segundo plano do quadro, com várias edificações, prédios medianamente altos e o que poderia ser considerado um viaduto. A paisagem revela ainda uma sutileza tropical, como um coqueiro no segundo plano, ao longe, no centro.

Em primeiro plano, vê-se a representação de duas figuras humanas e que marcam a mudança na escolha da simetria da arte moderna e a forma caricatural de representar as figuras humanas. Colocadas de forma a fazer par com as duas estruturas em forma de colunas em metal do viaduto, essas figuras conferem vida e movimento ao quadro juntamente com as linhas sinuosas e centrais sugerindo um curso d'água. $\mathrm{O}$ equilíbrio desse conjunto é estabelecido pela solidez da árvore à esquerda, cujo contraste da grande copa circular verde se contrapõe às faces pequenas e circulares das figuras humanas.

Em resumo, o primeiro plano é marcado pelas formas arredondadas, circulares e linhas sinuosas, pelo verde, o laranja e o amarelo e onde se encontram as demudadas figuras humanas; é o plano do movimento. No segundo plano estão as edificações predominantemente brancas, cinzas e os tons de azul, em cuja representação predominam as linhas retas horizontais e verticais, cujo repouso é quebrado unicamente pelo coqueiro ao centro, um ícone da temática tropicalizada e da brasilidade que Tarsila elegeu retratar nas obras desse período primitivista de sua carreira.

Francisco Rebolo Gonzáles (São Paulo, 1903 - São Paulo, 1980), pintor paulistano, foi fundador do Grupo Santa Helena juntamente com Volpi, Clóvis Graciano, Aldo Bonadei, Fúlvio Pen- nacchi, Humberto Rosa, Manoel Martins, Mário Zanini e Rizzotti em 1935. O grupo de artistas se reunia em ateliês no edifício Santa Helena na Praça da Sé, em São Paulo, com o objetivo de trocar experiências, técnicas e realizar estudos. Quase todos os integrantes do grupo eram imigrantes ou descendentes de imigrantes de origem humilde e seus trabalhos caracterizavam-se pelo uso de uma linguagem própria que ao mesmo tempo que se distanciava da elite do Modernismo pode ser considerada como um forte registro do cotidiano paulista e da Arte Moderna das décadas de 1930 e 1940.

Além das paisagens, Rebolo dedicou-se também a outros gêneros e técnicas, como as naturezas-mortas e a xilogravura, mas a paisagem era sua preferida. Apesar de autodidata, Rebolo foi também um estudioso de técnicas e materiais, por isso muitas vezes pintava ao ar livre na busca por resultados diferentes. Os quadros "Rua do Carmo" (fig. 03) de 1936 e "Praça Clóvis" (fig. 04) de 1944 foram pintados da janela do ateliê do Palacete Santa Helena. Já o quadro "Barra Funda" (fig. 07) é de 1968, período em que Rebolo se encontrava numa fase de retomada das cores claras, dos meio-tons que caracterizam as paisagens da fase inicial de sua carreira.

Rebolo foi um artista engajado, participou da criação do Sindicato dos Artistas Plásticos e Compositores Musicais em 1936 e foi também integrante da Família Artística Paulista-FAP, um grupo de artistas que buscava a apuração da técnica e das formas de produzir arte.

Os quadros "Rua do Carmo", "Praça Clóvis" e "Barra Funda" apresentam exatamente a simplicidade e a humildade que Rebolo buscava nas paisagens. Os três quadros mostram paisagens de uma 
São Paulo em plena transição. A linha do horizonte, em "Rua do Carmo" e "Praça Clóvis", ainda fica num plano bem afastado e é possível deslumbrar uma diminuição no gradiente da densidade das edificações. O relevo, à distância, apresentase com muitas áreas de solo exposto e relativamente pouco ocupado. A presença de pedestres nestas paisagens é muito pequena ou quase nula. "Rua do Carmo" apresenta uma arquitetura que fala por si própria, são prédios baixos de três andares cujas janelas ovaladas na parte superior combinadas com as linhas horizontais conferem movimento ao quadro. Os jardins escuros à direita, atrás das construções e o armazém na parte central inferior do quadro prendem o nosso olhar nas janelas, localizadas na faixa central. Pode-se fazer uma analogia, imaginado que os jardins são cabelos simbólicos, o armazém é a boca calada e as janelas são os olhos que dizem tudo, como se a região central fosse a cabeça e o corpo da cidade, cujos membros ainda estão se estendendo para além dali.

Oito anos depois, a cidade expande-se em "Praça Clóvis", e o que prevalece nesse quadro é o esquema triangular, a Igreja à direita, o prédio de dois andares no centro para a esquerda em primeiro plano e o grande edifício à esquerda em segundo plano constituem os pilares dessa paisagem urbana cujos primeiros arranha-céus começam a mudar a linha do horizonte de lugar. Em "Praça Clóvis" o colorido e a luz já não são mais tão vibrantes quanto em "Rua do Carmo", os tons variam sobre uma mesma cor. A presença dos pedestres também é insignificante neste quadro. Porém todo o movimento da composição encontra-se no sentido vertical, dado pelas linhas da igreja, dos postes, dos edifícios e das janelas alongadas no mes- mo sentido. Portanto, a área central da cidade inicia fortemente a sua verticalização.

"Barra Funda", de 1968, mostra uma paisagem diferenciada. É uma paisagem de um fragmento da cidade que marca um momento de transformação das atividades econômicas ali estabelecidas. Barra Funda é um bairro marcado pela intensa atividade industrial e instalação das Indústrias Matarazzo. O quadro mostra um período em que as marcas dessa atividade ainda são fortes na paisagem. Os três conjuntos de armazéns dispostos no primeiro plano e o trem no centro à esquerda, apesar do brilho e da importância no conjunto, não afasta o olhar para a força e o simbolismo das chaminés distribuídas por toda a paisagem.

Mário Zanini (São Paulo, 1907 - São Paulo, 1971), filho de humildes imigrantes italianos, é um artista paulistano que trabalhou ao lado de Rebolo no Grupo Santa Helena, na FAP e também na criação do Sindicato dos Artistas Plásticos. Paisagista e marinhista, Zanini chegou a experimentar outros gêneros, como algumas composições abstratas, mas nunca deixou de lado a representação da temática social. Zanini era companheiro de Volpi e Rebolo no registro ao ar livre da periferia paulistana. Assim como Rebolo tinha preferência pela simplicidade das paisagens ligadas ao proletariado paulistano.

O quadro "Tietê" (fig. 04) é um forte registro histórico-cultural da cidade de São Paulo. O quadro mostra uma paisagem e um momento que ficaram perdidos na memória pois a imagem de uma alegre e festiva regata nas águas do rio Tietê, margens com farta vegetação é quase inimaginável para quem olha hoje para o rio a partir da janela aberta de um carro nas suas marginais. 
Neste quadro, o tema importa mais que as características técnicas da composição, embora o colorido intenso, típico da obra de Zanini, as pinceladas detalhistas dos remos em posição oblíqua e a curvatura das canoas que conferem movimento ao quadro, as águas em tons claros ressaltados que mostram um rio vivo, pleno de atividade biológica e social sejam elementos importantes que se contrastam com a verticalidade das árvores na margem dos rios. Este quadro é um registro de uma cidade cujo eixo das atividades culturais já passou por momentos bem diversos do atual. $\mathrm{O}$ rio Tietê que hoje é um símbolo da poluição e do mau cheiro, já foi palco do lazer na São Paulo da década de 40.

Ainda hoje permanecem localizados às margens do Tietê diversos clubes que à época realizavam festivas regatas em suas águas limpas. Um detalhe curioso é que Francisco Rebolo, além de ter sido jogador de futebol é o criador do símbolo do Corinthians, um desses clubes localizados na margem do Tietê. Esse símbolo constitui-se de uma âncora e dois remos, objetos que hoje só fazem sentido a partir do estudo iconológico do símbolo.

Agostinho Batista de Freitas (Campinas, 1927 - 1997) é considerado um artista naïf - ingênuo. Descoberto por Pietro Maria Bardi no centro de São Paulo, ao vender e produzir seus quadros na rua, Agostinho revelou profundos conhecimentos de perspectiva e um olhar refinado da urbanidade de São Paulo. "Vista de São Paulo", (fig. 06) de 1952, foi pintado do alto do edifício do Banespa no centro da cidade, a partir de um desafio lançado por Bardi. Nesta composição, Agostinho mostra que possui um olhar seletivo sobre a cidade, pois ele consegue harmonizar a massa de edifícios distribuídos na região central da cidade, de forma a resultar num conjunto coeso, estruturado e revelador de uma metrópole em plena expansão.

Aquilo que visto do solo pode parecer caótico, na paisagem de Agostinho revela uma organização própria, um brilho e uma luminosidade desperta e silenciosa. O ritmo veloz, típico das grandes metrópoles, neste quadro simbolizado pela sobreposição dos edifícios, se quebra pelas pequenas manchas de áreas verdes e jardins espalhados em alguns pontos da paisagem. A linha do horizonte é quase inexistente no ângulo escolhido pelo artista. O que importa é ver a cidade e não onde ela termina, dessa forma o quadro traz clara a impressão de que a paisagem se estende para muito além da esquerda e da direita, quase se pode ver o que não está representado além da moldura.

Gregório Gruber, nascido na cidade de Santos em 1951, é um artista que se caracteriza pela intensa produção e experimentação de técnicas e materiais. Sempre buscando um ângulo diferenciado no olhar sobre o urbano, Gregório Gruber registra a solidão das formas da cidade de maneira poética, ressaltando os tons e as luzes de cada lugar.

De todos os quadros selecionados para este trabalho, os de Gregório Gruber são os que apresentam maior diversidade de materiais, explorando outras técnicas além do "óleo sobre tela" e dessa forma obtendo também um brilho e uma luminosidade diversa marcando um momento em que o urbano traz essa característica como identidade. Também são os quadros em que o enquadramento permite um ângulo de visão no qual a cidade se aproxima do observador, apesar da figura humana também não aparecer. Nestes, a proximidade do objeto observado dá a sensação de que o observa- 
dor também está presente de alguma forma, através da interpretação da paisagem que é absolutamente pessoal ressaltada pelo uso das cores e ênfase nas luzes.

O quadro "Sé" (fig. 08) de 1984 mostra a Catedral da Sé no centro da cidade, o marco zero iluminado. A Igreja tem sido símbolo do urbano desde a Idade Média e na cidade de São Paulo desde o século XVII tem sido demolida e reconstruída até que na década de 1950 chegou à forma atual e desde então passou a ser palco de muitas manifestações sociais, políticas e religiosas.

No quadro, as linhas de perspectiva levam o olhar para a Catedral que está representada em último plano, apesar de ser o elemento central do tema representado. Ela está sufocada em meio a um conjunto de altos edifícios, solitária, tanto quanto o centro da cidade fica quando termina o horário comercial. Todos saem mas ao invés de apagar as luzes, elas se acendem.

"Banco à noite" (fig. 09) de 1996 é outro quadro com um forte símbolo da cidade de São Paulo, o edifício Altino Arantes, sede do Banespa até sua venda para o Santander em 2000. Está entre os mais altos edifícios da cidade, de sua torre é possível ter uma visão de $360^{\circ}$ da cidade. Dali que Agostinho Batista de Freitas realizou o quadro "Vista de São Paulo". Neste quadro Gregório Gruber consegue captar forte sentido simbólico do edifício que pode ser visto de vários pontos da cidade em razão de sua iluminação. Imponente construção entre os vários edifícios do centro da cidade, o edifício Altino Arantes, representado bem no centro do quadro, é um forte símbolo do capital financeiro e da verticalização. Também representada de forma solitária, a arquitetura é o gran- de personagem, numa cidade onde as pessoas são levadas a olhar para cima, como nas linhas de perspectiva do quadro dispostas no sentido vertical, ninguém se olha no centro onde quem chama mais atenção são os prédios.

"Tamanduateí em azul" (fig. 10) de 2001 expressa a sensação típica do cotidiano da cidade, dias azuis, nublados, um rio preso entre paredes refletindo o brilho da luz do dia, mas que não inspira muito movimento, ao contrário é como se todo o movimento estivesse preso. Tamanduateí que em tupi quer dizer "rio de muitas voltas" representa uma ironia ao vê-lo retificado e canalizado e ainda guardar esse nome. Os tons azulados escuros da parede que margeia o rio à direita dão a clara noção do lodo grudado, mas o azul é também uma cor fria que denota um sentimento típico das paisagens urbanas revelador de tristeza e sobriedade. Não é uma sensação de prazer, os rios da cidade não lembram nem remotamente o clima festivo e barulhento do quadro "Tietê" de Zanini. É ainda silenciosamente que o Tamanduateí invade a avenida do Estado nos dias de chuva forte ou corre invisível nos trechos canalizados. Os rios da cidade são silenciosos personagens em meio a um horizonte de imponentes construções verticais. Nas suas margens quase nenhuma ou nenhuma vegetação, só avenidas que correm mais velozes que o rio, não dá tempo de olhar para ele.

\section{UM OLHAR ESTÉTICO SOBRE AS PAISAGENS}

DE São Paulo

São Paulo ainda guarda na toponímia um pouco da história de suas diversas chácaras que foram loteadas no século XX e deram lugar às extensas e movimentadas avenidas da cidade. A Chácara da 
Consolação é só um exemplo da rápida transformação que as áreas rurais sofreram com a expansão do urbano e o delineamento da metrópole paulistana, principalmente na segunda metade do século XX.

O quadro "Chácara da Consolação" é o registro de uma paisagem que permaneceu somente na memória simbólica da cidade. Esta paisagem é a imagem que o paulistano de hoje sonha adquirir como segunda residência fora do perímetro urbano, longe do barulho das grandes avenidas que agora passam onde antes era a chácara da Consolação.

Sem um planejamento coerente e organizado, a cidade de São Paulo expandiu-se e verticalizouse. Seus arruamentos foram tomando forma de maneira descoordenada. Os primeiros edifícios surgiram na década de 1920.

De qualquer maneira, os anos 1920 se constituem num marco importante do processo de transformação da cidade de São Paulo, no campo fértil da modernidade. As transformações que se operam, sob múltiplos aspectos, enunciam os tempos que estão por vir. A "Semana de 22" éo símbolo destes tempos. As vanguardas artísticas européias, evidentemente, têm um papel importante relacionado com essa Semana em São Paulo. (Souza, 2004, p. 39).

Uma nova estética inaugurou-se a partir dos movimentos dessas décadas iniciais do século XX. E com essa nova estética um novo olhar sobre a paisagem. Como marca e matriz, essa paisagem sugere novas criações. A partir da década de 1920 o velho passou a conviver com o novo. A arquitetura do centro de São Paulo cada vez mais viu suas antigas construções serem abraçadas por novos arranha-céus, muitos deles em estilo art nouveau, que utilizava materiais da indústria moderna, como ferro e cimento.

A transição por que passa São Paulo entre 1893 e 1924 é marcada por uma resignificação de valores, em todos os sentidos, mas, sobretudo culturais. Os padrões urbanísticos definem-se pelo moderno, e o moderno naquele momento têm as feições da São Paulo de Tarsila do Amaral. Parece uma paisagem feita com régua e compasso, cuja impessoalidade está simbolicamente registrada nas figuras sem feições no rosto. Exceto pelo quadro "Tietê", todos os outros confirmam essa percepção da cidade, a obra humana vem antes do humano na paisagem urbana.

A economia da região central transformou-se nesse início de século, a produção agrícola afastou-se progressivamente do centro e nele permaneceram e ampliaram-se as atividades de comércio, serviços e setores financeiros. A indústria cresceu em taxas significativas e também influiu na verticalização.

A intervenção na paisagem tem sido veloz desde então. $\mathrm{O}$ uso do solo e o zoneamento tiveram cada metro quadrado no centro da cidade cada vez mais valorizados, expulsando de certo modo uma parcela da população residente.

O arranba-céu, signo do processo de verticalização, não revela evidentemente, apenas uma forma em São Paulo. Revela, isto sim, uma identidade do processo de urbanização brasileiro e uma nítida possibilidade de morar que separa ricos e pobres. (Souza, 2004, P. 46).

"Rua do Carmo" é o registro de um núcleo central que ainda está se consolidando. Poucos pe- 
destres transitando mas um adensamento de construções que vai impor a convivência entre o velho e o novo no centro da cidade. Arranha-céus e arquitetura antiga cuja plasticidade inspira a recriação dessas paisagens na memória hoje.

"Tietê" tem o mesmo significado do quadro "Chácara da Consolação", é o registro da paisagem que se diluiu no tempo e no espaço, mas que poderia servir de matriz para uma inversão no significado simbólico do rio Tietê que já foi espaço de lazer e cultura e hoje é o símbolo do mau cheiro e da poluição principalmente para quem mora nos seus arredores. Esse estigma do rio sujo e poluído é um símbolo tão forte que para muitos habitantes da cidade, não importa qual seja o rio pelo qual você passa quando caminha pela cidade, é como se todos eles fossem o Tietê. Essa percepção é muito comum entre os jovens do ensino fundamental e foi comprovada na prática. Esse binômio rio-poluição é um símbolo também presente no quadro "Tamanduateí em azul".

Porém esse paradigma da poluição dos rios ainda não existe na década de 1940. Mas sua força atualmente mostra como a velocidade das transformações foi cruel em alguns aspectos do urbano em São Paulo.

Na seqüência, vê-se que de 1944 para 1952, a paisagem do centro de São Paulo toma definitivamente sua forma verticalizada e a imagem-símbolo do urbano em "Vista de São Paulo". O quadro "Praça Clóvis" é um registro do que posteriormente passa a ser denominado Centro Histórico, com alguns resquícios da antiga arquitetura.

"Barra Funda" é um fragmento de paisagem da cidade de São Paulo que representa a importância da indústria na formação da metrópole moderna, quando as indústrias ainda se localizavam na área urbana mais central. A transição da economia baseada na cultura do café para o aquecimento da industrialização tem suas marcas na paisagem de São Paulo, são as linhas férreas, os armazéns, as chaminés cilíndricas.

Sobre a cobertura vegetal, nota-se, principalmente em "Vista de São Paulo", que a expansão urbana não deixou espaço para grandes fragmentos de vegetação.

A cobertura vegetal perdeu lugar para a especulação da terra que se consolidou em toda a cidade, e poucas vezes foi considerada fator importante na estruturação urbana. A vegetação de campos úmidos das várzeas, as matas das colinas deram lugar inicialmente a loteamentos (regulares e clandestinos), distritos industriais, grandes avenidas e recentemente a shoppings centers, centros de eventos, centros de distribuição de abastecimento alimentar e de mercadorias, etc. (Furlan, 2004, p. 263).

As três últimas pinturas enquadram detalhes da paisagem de São Paulo que reafirmam os símbolos do urbano, como a catedral ao centro e o arranha-céu. Contudo, nestas pinturas, o ângulo de visão é mais horizontal, o olhar é mais analítico e pessoal do que nos quadros anteriores e permite levantar questões também mais específicas relacionadas à economia (torre do Banespa), ao poder e à religião (a Catedral e os movimentos sociais) ou então ao uso do solo e às enchentes. 


\section{ConClusÃo}

As paisagens de São Paulo representadas nos quadros selecionados expressam a solidão e espaços cujas edificações marcam sua identidade. É relevante o fato de que a figura humana não seja destaque em nenhum dos quadros selecionados. Se a partir desses quadros fosse realizado um quadro síntese, nele a figura humana não apareceria jamais senão por suas obras, suas construções e suas percepções coloridas ou não.

Essa característica ambígua da cidade, que se destaca por sua população gigantesca, que no entanto fica fora da imagem da paisagem (mas não dos processos!), reflete-se no sentimento de anonimato e abandono que grande parcela de seus habitantes e visitantes é portadora. Em meio a estatísticas sempre largas (número de habitantes, extensão da área urbana, quilômetros de avenidas e congestionamentos, etc.) parece natural que o indivíduo se sinta invisível, pois é difícil reconhecer a si mesmo e a extensão de seu gesto numa obra tão grande, o reflexo se perde no meio do tumulto das imagens.

O que se nota na seqüência de quadros analisada é que as edificações são personagens muito fortes no simbolismo da cidade, não importa qual o enquadramento que se faça, principalmente na região central de São Paulo, onde de dia ninguém se vê (ou se olha) em razão da velocidade do movimento, da pressa, do tempo ocupado, e à noite, não se vê ninguém, o centro é abandonado pelas pessoas. Mas antes de sair, não se apaga a luz, ao contrário, ela se acende para iluminar seus símbolos: a Catedral e seus arranha-céus (fig. 08 e 09).

Numa análise mais objetiva a linha do horizonte do quadro "Chácara da Consolação" (fig. 01) marca uma cidade que em fins do séc. XIX é pouco urbanizada nessa área que viria a ser parte da área central densamente construída. Pouco movimento e área ocupada por residências secundárias, viriam a configurar posteriormente uma fragmentação e intensa ocupação. O período em que este quadro foi pintado pode ser considerado como Era do Pré-Modernismo. Neste quadro há o predomínio da horizontalidade.

Entre o quadro "Chácara da Consolação" e "São Paulo" há um período de intensas modificações nos aspectos estéticos e de organização espacial. O quadro "São Paulo" marca uma ruptura com a maneira tradicional de pintar. $\mathrm{O}$ deslocamento dos eixos de simetria da pintura moderna, marcam também uma mudança na simetria dos grandes centros urbanos, com construções altas, a verticalização é uma característica da metrópole paulista que marca uma identidade, uma centralidade, valorização imobiliária e segregação, dentre outras características

Ainda que nos últimos anos São Paulo tenha passado por alguns deslocamentos da centralidade, quando a avenida Paulista, por exemplo, ganhou representatividade e tornou-se um forte símbolo como a "mais paulista das avenidas", a região central ainda continua carregada de simbologia. A Catedral da Sé ainda tem um vigor e o arranhacéu, mais especificamente o edifício Altino Arantes (torre do Banespa), é um símbolo imponente que pode ser avistado a vários quilômetros de distância, principalmente à noite, em razão de sua iluminação. São como bandeiras hasteadas que representam um estado, um modo de ser da cidade.

Como afirma Ponty (1961), "a visão do pintor é um nascimento continuado", dessa forma, as paisagens 
pintadas são marcas de um momento passado mas que continuam revelando e desvelando as paisagens de São Paulo e que podem contribuir na construção de um novo olhar e percepção sobre ela mesma, no qual seus habitantes possam melhor se reconhecer, uma cidade com feições e cujos reflexos dos gestos não se percam no tempo e no espaço. Uma cidade cuja iluminação não se apague para seus habitantes.
NOTAS

1 Definição de paisagem incluída no painel da exposição do acervo da Pinacoteca do Estado de São Paulo.

2 "Entre 1850 e 1950, as paisagens urbanas ocupam um lugar importante nas diferentes artes. A rua, a avenida, o movimento dos homens e das coisas, os anúncios e as vitrines, os calçadões dos cafés, o luxo e a pobreza são nas artes declinadas sobre suas numerosas facetas diurnas e noturnas." (tradução nossa) 


\section{FIGURAS}

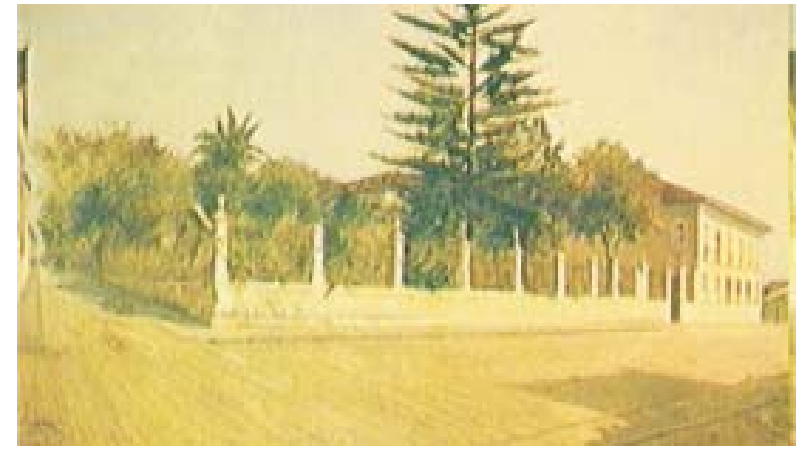

Figura 01- Chácara da Consolação, 1893

\section{Antônio Parreiras}

Óleo sobre tela $-78 \times 152 \mathrm{~cm}$, c.i.e.

Reprodução fotográfica: Horst Merke

Disponível em: <http://www.itaucultural.org.br>

Acesso em: 30/05/2006

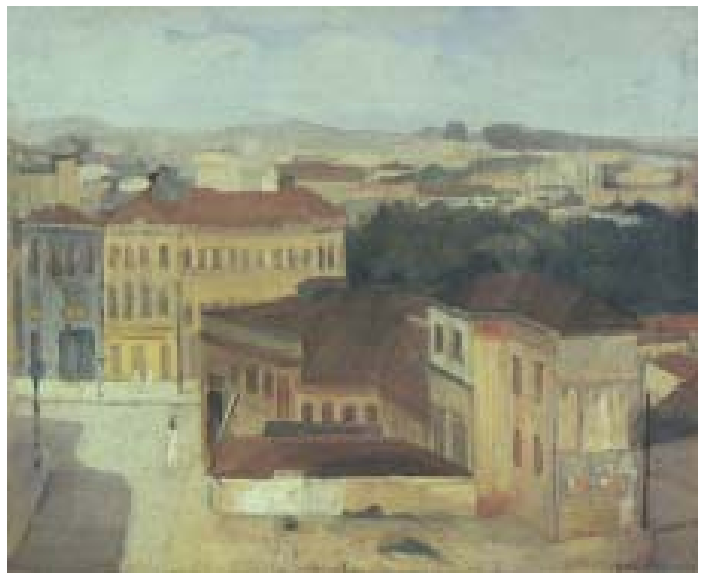

Figura 03 - Rua do Carmo, 1936

Francisco Rebolo

Óleo sobre tela -40 x 49 cm, c.i.d

Coleção: Chaim José Hamer

Reprodução fotográfica: Rômulo Fialdini

Disponível em: <http://www.itaucultural.org.br>

Acesso em: 30/05/2006

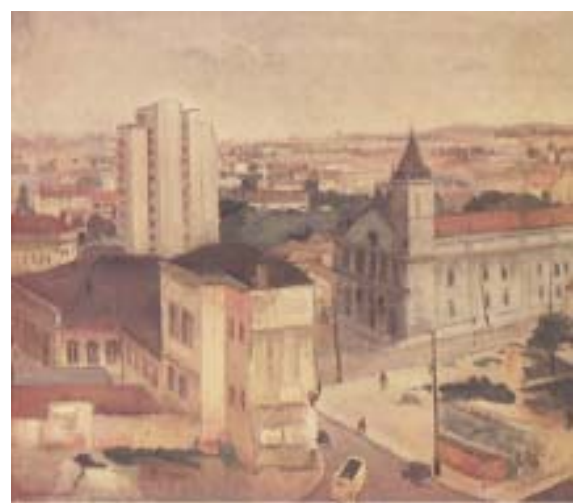

Figura 05 - Praça Clóvis, 1944

Francisco Rebolo

Óleo sobre tela, 66 x 77 cm, c.i.e.

Coleção Levy e Salomão Advogados

Disponível em: <http://www.itaucultural.org.br>

Acesso em: 30/05/2006

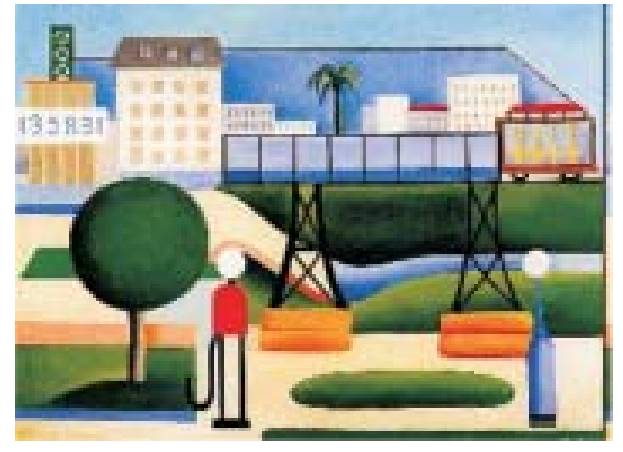

Figura 02 - São Paulo, 1924

Tarsila do Amaral

Óleo sobre tela - 67 × $90 \mathrm{~cm}$

Acervo: Pinacoteca do Estado - SP/SP

Reprodução fotográfica: Rômulo Fialdini

Disponível em: <http://www.itaucultural.org.br>

Acesso em: 30/05/2006

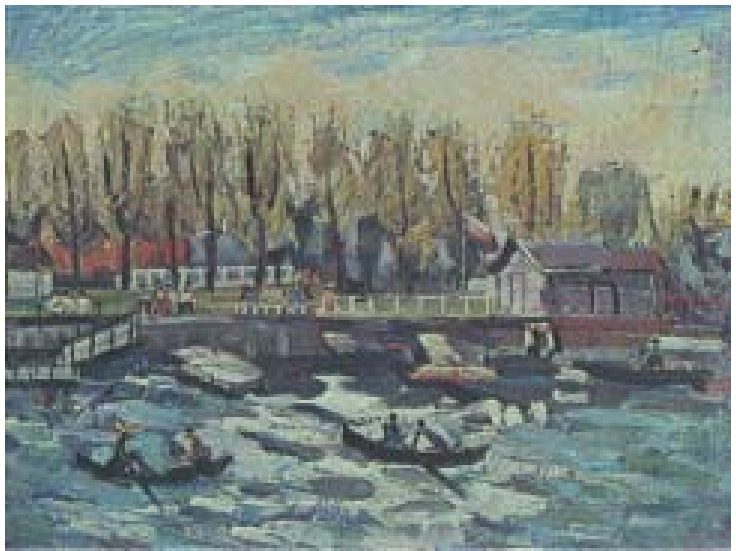

Figura 04 - Tietê, 1940

Mário Zanini

Óleo sobre tela $-33,5 \times 46 \mathrm{~cm}$, c.i.d.

Disponível em: $<$ http://www.itaucultural.org.br $>$

Acesso em: 30/05/2006

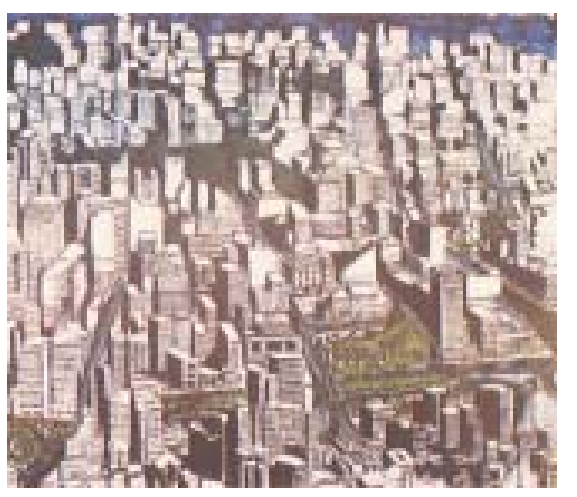

Figura 06 - Vista de São Paulo, 1952

Agostinho Batista de Freitas

Óleo sobre tela, $80 \times 100 \mathrm{~cm}$, c.i.e.

Disponível em: <http://www.itaucultural.org.br>

Acesso em: 30/05/2006 


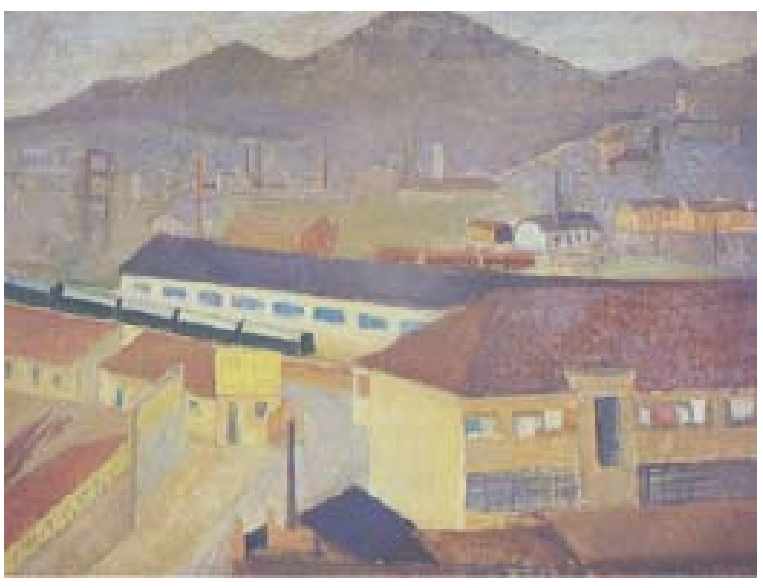

Figura 07 - Barra Funda, 1968

Francisco Rebolo

Óleo sobre hardboard - 49 × $65 \mathrm{~cm}$

Coleção Marina Basile, SP

Disponível em: <http://www.itaucultural.org.br>

Acesso em: 30/05/2006

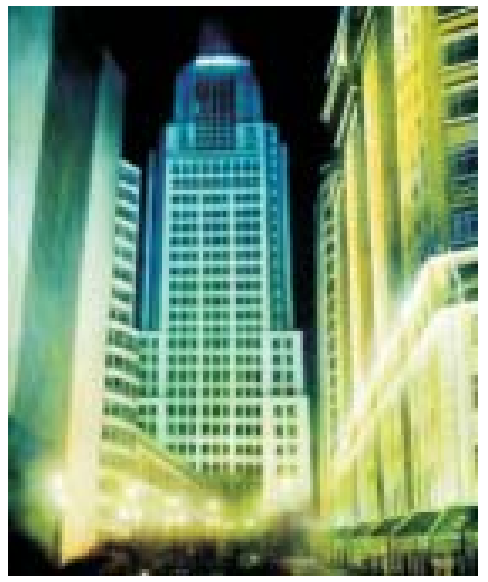

Figura 09 - Banco à noite, 1996

Gregório Gruber

Óleo sobre tela, $243 \times 180 \mathrm{~cm}$

Disponível em: <http://www.masp.art.br >

Acesso em: 04/03/2003

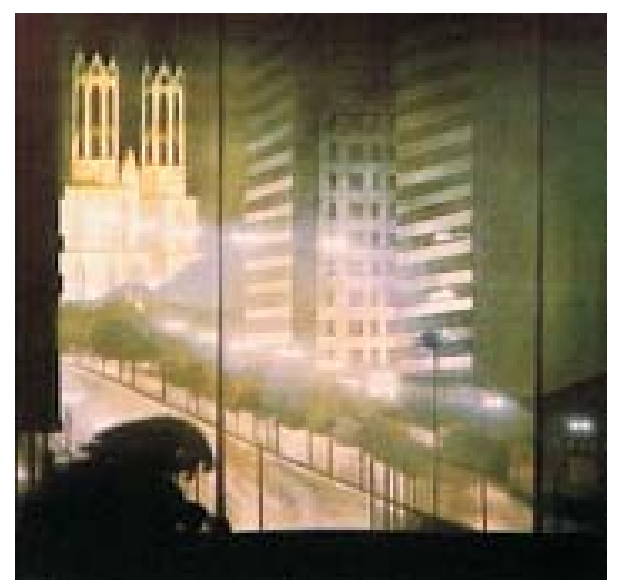

Figura 08 - Sé, 1984

Gregório Gruber

Acrílica sobre tela $-230 \times 220 \mathrm{~cm}$

Disponível em: $<$ http://www.itaucultural.org.br $>$

Acesso em: 30/05/2006

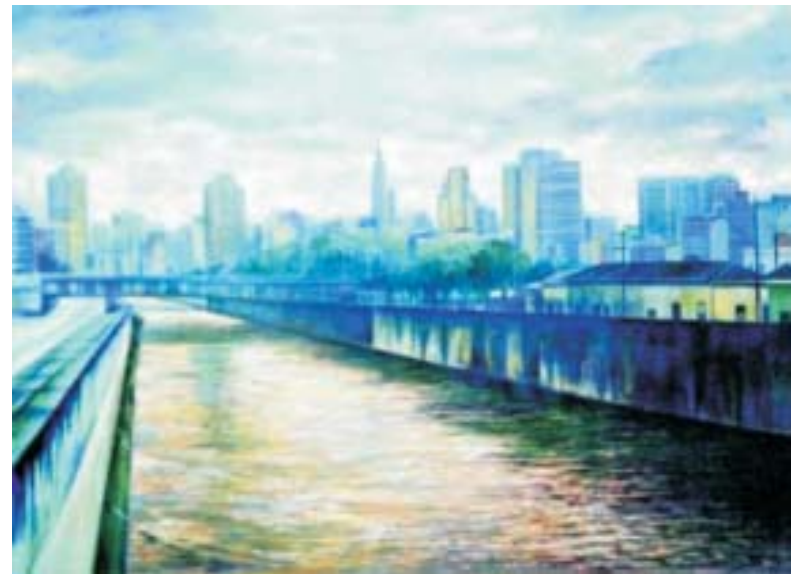

Figura 10 - Tamanduateí em azul, 2001

Gregório Gruber

Têmpera sobre Juta $-100 \times 140 \mathrm{~cm}$

Disponível em: <http://www.masp.art.br>

Acesso em 04/03/2003 
REFERÊNCIAS BIBLIOGRÁFICAS

ALVES, G. da A. Paisagens Metropolitanas. In: CARLOS, A. F. A.; OLIVEIRA, A. U. (Org.). Geografias de São Paulo: a metrópole do século XXI. São Paulo: Editora Contexto, 2004.

BÉGUIN, François. Le Paysage. France: Flammarion, 1995.

CORREAA, R. L.; ROSENDAHL, Z. (Org.). Paisagem, Tempo e Cultura. Rio de Janeiro: EdUERJ. Série Geografia Cultural, no2, 1998.

CORREAA, R. L.; ROSENDAHL, Z. (Org.). Introdução à

Geografia Cultural, Rio de Janeiro: Bertrand Brasil, 2003.

CORREAA, R. L.; ROSENDAHL, Z. (Org.). Paisagens, Textos e Identidade, Rio de Janeiro: EdUERJ, 2004.

FUNDAÇÃO FINAMBRÁS. Tarsila do Amaral - Projeto Cultural Artistas do Mercosul, Buenos Aires/Argentina: Finambrás, 199?

FURLAN, S. A. Paisagens Sustentáveis. In: CARLOS, A. F. A.; OLIVEIRA, A. U. (Org.). Geografias de São Paulo: a metrópole do século XXI. São Paulo: Editora Contexto, 2004.

GROUT, Catherine. Quels paysages dans l'art contemporain? In: CHENET, F. Le Paysages et ses Grilles (actes du colloque de Cerisy-la-Salle, 7 au 14 septembre 1992). Paris: L'Harmattan 1996

HÉRODOTE: REVUE DE GÉOGRAPHIE ET DE GÉOPOLITIQUE. Paysages en Action: Le Rivage des Syrtes? no 44, p. 66 , Paris: janvier-mars, 1987

MYANAKI, J. A Paisagem no Ensino de Geografia: Uma Estratégia Didática a partir da Arte. Dissertação (Mestrado) Departamento de Geografia da Faculdade de Filosofia, Letras e Ciências Humanas da Universidade de São Paulo. São Paulo, 149 p, 2003.

PAREYSON, Luigi. Os Problemas da Estética. Tradução Maria Helena Nery Garcez. 3a ed. São Paulo: Martins Fontes, 1997, 246 p. (Título original: I Problemi dell'Estetica. Marzorati: Editore Milano)
PONTY, M. M. O olho e o espírito. In: O olho e o espírito: seguido de $\mathrm{A}$ linguagem indireta e as vozes do silêncio e A dúvida de Cézanne. Trad. De Paulo Neves e Maria Ermantina Galvão Gomes Pereira. São Paulo: Cosac\&Naify, 2004.

RIOU, Gérard. Les Representations de la Nature: sur les Chemins Parallèles de l'Esthétique et de la Connaissance. In: CHATELIN, Y. \& RIOU, G. (Orgs.) Milieux et Paysages: Essai sur Diverses Modalites de Connaissance. Revue Recherches en Géographie. Paris: Masson, 1986.

SOUZA, M. A. Território e lugar na metrópole. In: CARLOS, A. F. A.; OLIVEIRA, A. U. (Org.). Geografias de São Paulo: a metrópole do século XXI. São Paulo: Editora Contexto, 2004.

TUAN, Yi-Fu. Topofilia: Um Estudo da Percepção, Atitudes e Valores do Meio Ambiente. Tradução de Lívia de Oliveira. São Paulo: Difel/Difusão Editorial S. A., 1980. (Título original:

Topophilia: A Study of Environmental Perception, Attitudes, and Values, by Prentice-Hall Inc., Englewood Cliffs, New Jersey).

\section{Sites consultados}

ITAÚ Cultural. Site oficial da Instituição, apresenta a programação de eventos nas diversas formas de expressão artística e, dentre várias enciclopédias, uma de artes visuais. Disponível em: <http://www.itaucultural.org.br $>$. Acesso em: 30 de maio de 2006.

MUSEU Antonio Parreiras. Site oficial do Museu com objetivo de divulgar e preservar a obra do artista. Disponível em: < http://www.sec.rj.gov.br/webmuseu/map.htm>. Acesso em: 30 de maio de 2006.

TARSILA do Amaral. Site oficial da artista brasileira com reproduções virtuais de algumas obras e biografia. Disponível em: <http://www.tarsiladoamaral.com.br $>$. Acesso em: 30 de maio de 2006.

GREGÓRIO Gruber. Site oficial do artista com textos críticos e reproduções de obras. Disponível em: $<$ http:// www.gregoriogruber.com.br/index.htm $>$. Acesso em: 30 de maio de 2006.

\section{ABSTRACT:}

THE POLYMORPHOUS LANDSCAPES PRESENT WITHIN THE CITY OF SÃO PAULO, THE LARGEST METROPOLIS OF LATIN AMERICA, ARE THE OBJECT OF ANALYSIS FOR THIS STUDY. THE TRANSFORMATIONS OF THESE LANDSCAPES, WHICH HAVE STRIKINGLY CONTRASTING CHARACTERISTICS, ARE EXAMINED BY MEANS OF THE REPRODUCTIONS OF TEN PAINTINGS PRODUCED bY CERTAIN BRAZILIAN ARTISTS BETWEEN 1893 AND 2001. THE ANALYSIS AND INTERPRETATION OF THESE PAINTINGS, PRODUCED bY ANTÔNIO PARREIRAS, TARSILA dO AMARAL, FRANCISCO REBOLO, MÁRIO ZANINI, AgOSTINHO BATISTA DE FREITAS AND GREgÓRIO GRUBER, PERMIt US tO TAKE ADVANTAGE OF THE COGNOSCITIVE ASPECT OF ART FOR THE ANALYSIS OF LANDSCAPES IN GEOGRAPHY. THIS APPROACH AIMS TO ADD THE ANALYSIS AND REFLECTION ON WORKS OF ART TO THE SUM OF ANALYTICAL METHODS AND INVESTIGATION IN GEOGRAPHY, BY CONSIDERING THE PAINTED LANDSCAPE AS A RECORD OF OBJECTIVE AND SUBJECTIVE ELEMENTS THAT CAN REVEAL A LOT ABOUT THE CULTURE OF A PEOPLE, THEIR TIME, AND THEIR DYNAMICS OF FORMATION AND TRANSFORMATION, AS WELL AS CONDITIONING NEW WAYS OF EXAMINING AND PERCEIVING LANDSCAPES.

KEY WORDS: LANDSCAPE PAINTING; LANDSCAPES OF SÃO PAULO; READING OF LANDSCAPES. 